$16^{\circ}$ USIHC - Congresso Internacional de Ergonomia e Usabilidade de USIHC Interfaces Humano Computador

CINAHPA

CINAHPA | 2017 - Congresso Internacional de Ambientes Hipermídia para Aprendizagem.

\title{
ANÁLISE DA INTERFACE DE UM LIVRO DIGITAL SOBRE ILUMINAÇÃO FOTOGRÁFICA DE ESTÚDIO
}

\section{ANALYSIS OF THE INTERFACE OF A DIGITAL BOOK ABOUT STUDIO PHOTOGRAPHIC LIGHTING}

\author{
Ana Leticia Oliveira do Amaral ${ }^{1}$, mestranda \\ Berenice Santos Gonçalves², Dra. \\ Volnei Antônio Matté ${ }^{3}$, Dr.
(1) Universidade Federal de Santa Catarina
e-mail: amaral.analeticia@gmail.com \\ (2) Universidade Federal de Santa Catarina \\ e-mail: berenice@cce.ufsc.br
(3) Universidade Federal de Santa Maria e-mail: volnei.a.m@gmail.com

\begin{abstract}
Palavras-chave: design de interfaces, livro digital interativo, iluminação fotográfica
\end{abstract}
\begin{abstract}
O livro digital interativo pode reunir uma diversidade de recursos que tornam o conteúdo expressivo e dinâmico. Nesse sentido, destaca-se a capacidade de ser empregado como recurso de aprendizagem. Com base nessas afirmações e na observação de aulas de fotografia em contexto de graduação, foi possível constatar a oportunidade de elaboração de um livro digital sobre composição de luzes de estúdio para fotografia. Diante do exposto, o objetivo principal deste artigo é relatar as etapas do projeto e a avaliação do livro digital interativo desenvolvido. Os resultados mostram, dentre as contribuiç̃oes, que a composição do conteúdo, em relação à utilização de linguagem verbal e visual temática, foi eficiente para motivar o leitor. Além disso, o projeto também foi considerado eficaz como método de consulta. Contudo, a navegação e o desenho dos ícones foram considerados pontos a serem melhorados.
\end{abstract}

\section{Key-words: interface design, interactive digital book, photographic lighting}

The interactive digital book can bring together a diversity of resources that make the content expressive and dynamic. In this sense, the capacity to be employed as a learning resource is highlighted. Based on these affirmations and the observation of photography classes in the context of graduation, it was possible to verify the opportunity to elaborate a digital book on composition of studio lighting for photography. In view of the above, the main objective of this article is to report the stages of the project and the evaluation of the digital interactive book developed. The results show, among the contributions, that the content composition, in relation to the use of verbal and thematic visual language, was efficient to motivate the reader. In addition, the project was also considered effective as a consultation method. However the navigation and the icons design were considered points to be improved. 


\section{$16^{\circ}$ \\ ERGODESIGN USIHC CINAHPA}

\section{Introdução}

Os dispositivos móveis de leitura, populares atualmente, proporcionam diversas maneiras de apresentação de informações, sendo uma delas os livros digitais interativos. De acordo com Licht et al. (2016) o livro digital possui características próprias, visto que reúne uma diversidade de recursos que tornam o conteúdo expressivo e dinâmico. Ainda segundo os autores, entre as finalidades do livro digital interativo, destaca-se a capacidade de ser empregado como recurso de aprendizagem.

Considerando as afirmações acima, a observação de aulas de fotografia em contexto de graduação, e o apoio de um professor da área, foi possível constatar a oportunidade da construção de um livro digital sobre o tema "fundamentos da iluminação de estúdio".

Diante disso, percebeu-se a necessidade de desenvolver uma ferramenta equilibrada entre forma (estética) e função (usabilidade), fácil e prática, na qual o leitor fosse o centro das preocupações [ROYO, 2008]. Nesse sentido, esse material poderia ser capaz de auxiliar o leitor na composição da iluminação para as produções fotográficas.

Frente a esse cenário, este artigo apresenta o processo de design e avaliação de um livro digital que teve por objetivo estimular a aprendizagem sobre os conceitos de iluminação, de modo dinâmico e interativo. Para tanto, este estudo foi dividido em três seções, que abordam: a fundamentação teórica que apoiou a pesquisa, o processo de design do livro e a avaliação da interface realizada por especialistas.

\subsection{Design de Interação e Design de Interfaces}

Para Kolko (2011), em uma definição mais abrangente, o Design de Interação caracteriza a criação de um diálogo (físico e emocional) entre pessoas e produtos, sistemas ou serviços. De acordo com Saffer (2010), o Design de Interação empenha-se em encontrar soluções para produtos que envolvem a interação com o usuário, tendo como objetivo não apenas a usabilidade, mas também a utilidade e a diversão. Pode-se dizer que $16^{\circ}$ Ergodesign - Congresso Internacional de Ergonomia e Usabilidade de Interfaces Humano Tecnológica: Produto, Informações Ambientes Construídos e Transporte

$16^{\circ}$ USIHC - Congresso Internacional de Ergonomia e Usabilidade de Interfaces Humano Computador

CINAHPA | 2017 - Congresso Internacional de Ambientes Hipermídia para Aprendizagem.

o processo de Design de Interação acontece envolvendo três agentes: o usuário, a tecnologia e o designer. Sendo assim, como afirma Preece, Rogers e Sharp (2005), a essência do design de interação é fornecer suporte às atividades cotidianas das pessoas para melhorar a forma como elas se comunicam, trabalham e utilizam produtos interativos.

Quanto ao Design de Interfaces, para Bonsiepe (2015), a interface é "o espaço no qual se estrutura a interação entre corpo, ferramenta (objeto ou signo) e objetivo da ação" [BONSIEPE, 2015, p. 111]. Em síntese, o Design de Interfaces é o encontro do Design Visual com o Design de Interação.

\subsection{Conteúdo Interativo}

O processo de compreensão de uma obra pode ser manifestado a partir de quatro etapas que formam a aprendizagem progressiva: dados básicos, informações, conhecimento e sabedoria. Kolko (2011, p. 42) explica que, apesar de terem pouco valor os dados quando isolados, representam as unidades isoladas do conteúdo. A informação descrita como dados significativos é formada pela união dos elementos de relação semântica que geram uma experiência sensorial, da qual a visão é a mais comum. Tais elementos, quando combinados com a finalidade de formar algum argumento ou teoria, são classificados como conhecimento. $\mathrm{O}$ alcance de conhecimento ocorre no decorrer do tempo, enquanto isso, o comportamento se manifesta por influência da sabedoria, que constitui uma nova e original aplicação do conhecimento.

Dessa forma, um livro digital interativo pode ser considerado um instrumento de transferências de informação, o qual pode também oferecer imersão em experiência ao usuário, visto que o leitor pode até não experimentar as funcionalidades de determinado objeto, mas pode adquirir conhecimento sobre suas funcionalidades.

\section{Procedimentos metodológicos}

De acordo com Prodanov e Freitas (2013), este artigo é de natureza aplicada, com abordagem qualitativa e quanto aos objetivos, é classificado 


\section{$16^{\circ}$ \\ ERGODESIGN USIHC CINAHPA}

$16^{\circ}$ Ergodesign - Congresso Internacional de Ergonomia e Usabilidade de Interfaces Humano Tecnológica: Produto, Informações Ambientes Construídos e Transporte

$16^{\circ}$ USIHC - Congresso Internacional de Ergonomia e Usabilidade de Interfaces Humano Computador

CINAHPA | 2017 - Congresso Internacional de Ambientes Hipermídia para Aprendizagem. como exploratório. Sendo assim, a investigação foi estruturada em quatro principais etapas: (I) Levantamento teórico sobre luz e iluminação de estúdio; (II) Design do livro digital; (III) Avaliação do livro por especialistas e (IV) Resultados e discussões.

\subsection{Levantamento teórico sobre luz e iluminação de estúdio}

A pesquisa sobre luz e iluminação de estúdio, realizada durante a primeira fase do desenvolvimento da pesquisa, buscou apoiar o desenvolvimento do projeto do livro digital.

Como afirmam Hunter, Biver e Fuqua (2014), a luz é o elemento primordial à fotografia, pois é responsável por sua criação, por meio de sombras, revelando formas e texturas, entre outras possibilidades, de acordo com a imaginação do fotógrafo. Por isso, presume-se que todo fotógrafo ou aprendiz deva ter conhecimento sobre os conceitos de iluminação fotográfica.

Desse modo, buscou-se abordar o conceito de luz apoiado nas teorias de Newton (Teoria Corpuscular da Luz), Huygens (Modelo Ondulatório) e Einsten (fótons), as quais, segundo Barthem (2005), são a base dos estudos sobre a radiação eletromagnética desde o século XX até hoje. Com isso, foi possível conceituar o espectro luminoso, a temperatura de cor e o balanço de branco - que é o ajuste feito na câmera para corrigir as cores -, assim como apresentar as especificidades da luz natural e luz disponível, ou seja, as luzes que nos cercam no cotidiano, sem a nossa intervenção. Ainda foram tratados conceitos básicos da luz do ponto de vista da fotografia.

Segundo Präkel (2010), o controle sobre a luz que se tem em um estúdio engloba não só a direção e a quantidade de luz, mas também a sua qualidade.

Em síntese, em um estúdio, o fotógrafo tem total controle sobre a incidência de luz e pode moldá-la com o auxílio dos esquemas clássicos de iluminação e dos diferentes modificadores.

\subsection{Design do livro digital}

O método de projeto escolhido para orientar a elaboração do referencial prático e do produto foi o Projeto E, desenvolvido por Meurer e Szabluk
(2010) que compreende oito etapas. Contudo, para esta pesquisa, decidiu-se por dividi-lo em duas grandes seções, sendo elas: compreensão do projeto e configuração do produto. Os tópicos das seções serão apresentados a seguir.

\section{Compreensão do projeto}

I. Contextualização: consiste na etapa inicial e tem por objetivo identificar, definir e delimitar o problema. Como subfases, nesta pesquisa, foram escolhidas: (a) Situação inicial bem definida (SIBD) e situação final bem definida (SIFB); (b) Questões projetuais; (c) Taxonomia; (d) Condição atual e condição pretendida; (e) Identificação dos usuários e (f) Equalização dos fatores projetuais.

II. Desconstrução: englobou uma ampla análise e avaliação dos conteúdos, conceitos e contextos que serviram de referência para o desenvolvimento do projeto. Nesta etapa, foi desenvolvida uma (a) linha do tempo, que buscou investigar produtos ou nichos de produtos pioneiros no contexto do projeto. Ainda na fase de desconstrução, foi realizado um levantamento de (b) similaridades e referências de aplicativos da área de fotografia, (c) análises estrutural, morfológica e funcional e um (d) comparativo de funcionalidades de três aplicativos e um site, sendo eles a Katachi Magazine, o aplicativo WWF Together, a revista Mine e o site Be moved.

Esse levantamento buscou elencar as especificidades de cada um desses objetos, através da análise da organização do conteúdo, da tipografia, das imagens e da consistência nas interações e sinalizações, resultando em um comparativo de funcionalidades. Essas ferramentas escolhidas para um quadro comparativo influenciam diretamente na manutenção da atenção do usuário, ou seja, quanto mais detalhadas e bem projetadas (aliadas ao conteúdo) forem as ferramentas, maior será o tempo dedicado pelo usuário ao produto.

II. Verificação: nesta fase foi possível, considerando as informações obtidas nas etapas anteriores, definir uma lista de restrições, requisitos e possibilidades a serem consideradas no novo produto.
Realização:

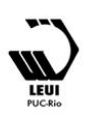


$16^{\circ}$ Ergodesign - Congresso Internacional de Ergonomia e Usabilidade de Interfaces Humano Tecnológica: Produto, Informações Ambientes Construídos e Transporte

$16^{\circ}$ USIHC - Congresso Internacional de Ergonomia e Usabilidade de Interfaces Humano Computador

CINAHPA | 2017 - Congresso Internacional de Ambientes Hipermídia para Aprendizagem.

\begin{tabular}{|l|l|}
\hline \multicolumn{1}{|c|}{ O que? } & \multicolumn{1}{c|}{ Como? } \\
\hline Usabilidade & $\begin{array}{l}\text { Padrão gráfico-visual } \\
\text { Linguagem do usuário } \\
\text { Sinalização evidente nas } \\
\text { interaçôes }\end{array}$ \\
\hline Composição Estético- & $\begin{array}{l}\text { Criar malhas para a } \\
\text { organização do conteúdo } \\
\text { Iconografia padronizada de } \\
\text { acordo com a temática } \\
\text { escolhida } \\
\text { Imagens atrativas e } \\
\text { condizentes com o conteúdo }\end{array}$ \\
\hline Legibilidade & $\begin{array}{l}\text { Fontes de tamanhos e } \\
\text { espaçamento adequados } \\
\text { Iconografia com média-alta } \\
\text { ordem gráfica }\end{array}$ \\
\hline Conteúdo & $\begin{array}{l}\text { Apresentação do conteúdo } \\
\text { textual de forma divertida }\end{array}$ \\
\hline
\end{tabular}

Figura 1: Quadro de requisitos para o projeto. Fonte: dos autores, 2015

\section{Configuração do produto}

I. Reconstrução: esta fase diz respeito às etapas de escopo, estrutura e esqueleto do projeto, ou seja, geração de alternativas.

II. Definição de ferramentas, funcionalidades e conteúdos: esta etapa consiste em estabelecer a organização e a hierarquia entre os conteúdos, assim como as ferramentas e funcionalidades. Para isso foi utilizada a técnica de prototipagem rápida card sorting (cartões sortidos). Com isso, a primeira fase foi descrever as informações nos cartões de forma aleatória para então, de acordo com a sequência do conteúdo, organizá-los em um organograma hierárquico. Nesta etapa, ainda foi necessário compor o conteúdo textual para uma melhor visualização das ferramentas e funcionalidades. Os textos foram estruturados com base na linguagem dialogada para remeterem à temática escolhida, a fim de envolver o leitor e tornar a leitura dinâmica e divertida. As informações foram estruturadas visando a melhor forma de continuidade do assunto para facilitar a compreensão do usuário. Com isso, definiu-se o sentido de navegação a partir de capítulos e orientação da página como horizontal.

III. Identidade: A definição da assinatura visual do livro digital partiu de pesquisas filtradas utilizando palavras-chave, como vintage, fundos desfocados, otimismo e divertido. A partir dos resultados visuais, optou-se por uma temática retro com foco nos anos 50.

Assim, o protótipo do livro intitulado Sopa no Mel possui uma navegação horizontal por capítulos e vertical por conteúdo, ou seja, para navegar entre capítulos diferentes é necessária uma transição horizontal, já para consultar o assunto do capítulo em si a transição deve ser vertical. O conteúdo foi dividido em cinco capítulos e o livro é composto por: capa, instruções, apresentação, sumário, capítulo 1 (O que é luz?), capítulo 2 (Princípios de Iluminação), capítulo 3 (Esquemas Clássicos), capítulo 4 (Modificadores), capítulo 5 (Imagens) e créditos.

Capa: buscou-se construir uma capa divertida que estimule o interesse do leitor já no primeiro contato. Os elementos utilizados foram escolhidos para reforçarem a ideia do conteúdo que o usuário irá encontrar.

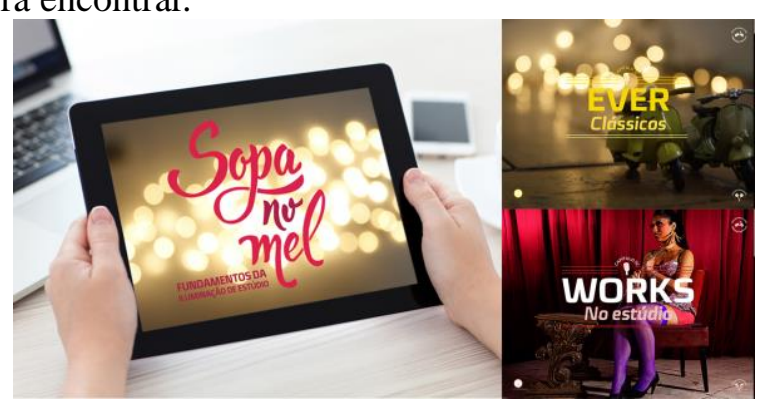

Figura 2: Capas do protótipo. Fonte: dos autores, 2017

Instruções: apresentam uma explicação, através de ícones e texto, sobre a forma de utilizar o livro.

Apresentação: explicita o que será encontrado no decorrer da leitura e em que contexto o livro digital interativo foi concebido. Capítulo 1 - Magic: este é o capítulo introdutório que tenta responder a pergunta “o que é luz?". São apresentadas as teorias da luz mais relevantes ao mundo fotográfico. Capítulo 2 - Rules: são apresentadas ferramentas que são utilizadas como princípios fundamentais de iluminação, através do uso de diferentes estilos de interação. Capítulo 3 - Ever: é dedicado aos esquemas clássicos de iluminação de estúdio. Sendo que há também uma página voltada a explicar o que é um estúdio fotográfico. Capítulo 4 - Works: apresenta as características 


\section{$16^{\circ}$ \\ ERGODESIGN USIHC CINAHPA}

$16^{\circ}$ Ergodesign - Congresso Internacional de Ergonomia e Usabilidade de Interfaces Humano Tecnológica: Produto, Informações Ambientes Construídos e Transporte

$16^{\circ}$ USIHC - Congresso Internacional de Ergonomia e Usabilidade de Interfaces Humano Computador

CINAHPA | 2017 - Congresso Internacional de Ambientes Hipermídia para Aprendizagem. dos modificadores de luz, devido à sua importância em um estúdio fotográfico. Capítulo 5 - Baby: é predominantemente composto por imagens, utilizadas para exemplificar diferentes tipos de iluminação e ambientes. Créditos: é dado reconhecimentos aos colaboradores do projeto.

Como parte de reforço ao conteúdo interativo, fezse necessário o desenvolvimento de ícones que identificassem o tipo de interação que está sendo apresentada para orientar o leitor. Dessa forma, para o desenvolvimento dos ícones foram selecionadas as principais tarefas e escolhidos os desenhos que melhor representariam a ação e ainda remetessem à temática.

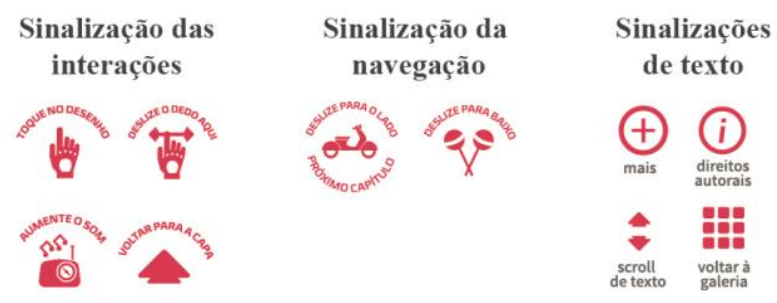

Figura 3: Ícones. Fonte: arquivos do projeto

\subsection{Avaliação do livro por especialistas}

Para fins de avaliação do cumprimento dos objetivos pretendidos pelo livro digital interativo, optou-se por consultar especialistas na área a partir de um questionário qualitativo - construído com base nos requisitos levantados na fase de verificação. A avaliação foi realizada individualmente com quatro especialistas, durante a segunda semana de março de 2017, sendo três participantes professores universitários, dois da área de design editorial e um de fotografia doutores que atuam em uma instituição externa ao desenvolvimento do projeto - e um doutorando da área de mídia.

No início de cada consulta, foi explanado o objetivo da aplicação do questionário. Após o uso do livro digital interativo, por um período aproximado de 10 minutos, cada analista respondeu um questionário impresso composto por duas partes. A primeira tinha o intuito de reconhecer o perfil do participante e a segunda visava à avaliação geral do livro digital interativo. Findadas as consultas, os resultados foram compilados e demonstrados a seguir.

\subsection{Resultados e discussões}

Para iniciar as discussões acerca da avaliação, a síntese do grau de familiaridade que os especialistas têm com os dispositivos móveis de leitura é que metade dos especialistas, A e D, consideram que dominam a tecnologia completamente e dois, B e C, dominam em parte.

Quanto à avaliação geral do livro digital interativo, três dos especialistas concordam que a dinâmica de navegação está boa e um deles a considerou excelente. Contudo, o especialista A acredita que o ritmo de leitura pode ser quebrado devido à alternância horizontal/vertical dos conteúdos. Já o especialista B destaca a necessidade de estar presente uma forma mais rápida de retorno ao sumário. $\mathrm{E}$ o especialista $\mathrm{D}$ recomenda manter os botões de navegação na mesma localização em diferentes telas.

Todos os especialistas concordam que não há falta de informações complementares, assim como todos os especialistas consideram que o uso de uma linguagem temática motiva o leitor. Dois dos participantes concordam que a linguagem visual temática (ícones, ilustrações e fotografias) seria eficaz para motivar o aluno a consultar o livro. Por outro lado, os especialistas A e D concordam em parte, visto que consideram que os ícones apesar de visualmente atrativos, precisam ser mais claros quanto aos objetivos para não confundir o leitor. O quadro a seguir busca ressaltar as principais contribuições sugeridas pelos especialistas para o aperfeiçoamento da interface.

\begin{tabular}{|l|l|}
\hline Participante & Contribuição \\
\hline Especialista A & $\begin{array}{l}\text { A alternância horizontal/vertical pode } \\
\text { confundir e quebrar o ritmo de leitura dos } \\
\text { conteúdos. }\end{array}$ \\
\hline Especialista A & $\begin{array}{l}\text { Os ícones poderiam ser mais } \\
\text { representativos quanto aos seus objetivos. }\end{array}$ \\
\hline Especialista B & $\begin{array}{l}\text { Poderia facilitar a localização de um } \\
\text { conteúdo específico. }\end{array}$ \\
\hline Especialista D & $\begin{array}{l}\text { Apesar de ficarem visualmente mais } \\
\text { atrativos (botões), pode confundir uma } \\
\text { comunicação clara e eficiente. }\end{array}$ \\
\hline
\end{tabular}

Figura 4: Principais contribuições qualitativas dos especialistas. Fonte: dos autores, 2017
Realização:
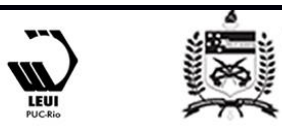


\section{$16^{\circ}$ \\ ERGODESIGN USIHC CINAHPA}

Três dos quatro especialistas consideram a quantidade de animações suficientes e um insuficiente. Ainda, três participantes concordam que o livro digital interativo é eficiente como método de consulta rápida, já o especialista $B$ concorda em parte, apontando que deveria haver uma maior facilidade em localizar conteúdos específicos. A mesma opinião se repetiu em relação à falta de feedbacks.

\begin{tabular}{|l|l|}
\hline Pontos Positivos & Pontos a serem aprimorados \\
\hline - composição do conteúdo & - formas de retonar ao sumário \\
\hline $\begin{array}{l}\text { - as linguagens verbal e visual } \\
\text { temática motivam o leitor }\end{array}$ & $\begin{array}{l}\text { - apresentar de forma mais clara } \\
\text { a dinâmica de navegação }\end{array}$ \\
\hline - método de consulta eficaz & $\begin{array}{l}\text { - feedbacks de retorno ao início } \\
\text { e de ir para outros conteúdos }\end{array}$ \\
\hline & $\begin{array}{l}\text { - botões mais claros quanto aos } \\
\text { seus objetivos }\end{array}$ \\
\hline
\end{tabular}

Figura 5: Pontos positivos e pontos a serem aprimorados. Fonte: dos autores, 2017

\section{Considerações Finais}

$\mathrm{O}$ ambiente digital é um meio frequente onde a troca de informações, experiências e conhecimentos acontece constantemente, de modo dinâmico e interativo. Como ressalta Portugal (2010) há necessidade de se investigar novos modelos, métodos e abordagens para o design de interação, novas maneiras de apresentação de conteúdos diferentes das tradicionais. Acredita-se que a união do conteúdo sobre iluminação fotográfica e o livro digital interativo permite novas formas de retenção e aprendizagem das informações ao leitor.

Desse modo, considera-se que o objetivo da pesquisa relatada foi alcançado, pois foram obtidas informações relevantes em relação aos fundamentos de iluminação e interação, assim como foi possível desenvolver e analisar o livro digital interativo. Além disso, ficou claro aos pesquisadores a necessidade de testes com os usuários, visto que apesar dos resultados positivos aprimoramentos - conforme apontado pelos especialistas consultados - poderiam ser alcançados, cabendo ainda novas análises da interface, assim como testes com usuários $16^{\circ}$ Ergodesign - Congresso Internacional de Ergonomia e Usabilidade de Interfaces Humano Tecnológica: Produto, Informações Ambientes Construídos e Transporte

$16^{\circ}$ USIHC - Congresso Internacional de Ergonomia e Usabilidade de Interfaces Humano Computador

CINAHPA | 2017 - Congresso Internacional de Ambientes Hipermídia para Aprendizagem. aplicados no ambiente para o qual o livro digital interativo foi inicialmente proposto - o estúdio fotográfico.

\section{REFERÊNCIAS BIBLIOGRÁFICAS}

BARTHEM, R. A luz. São Paulo: Editora Livraria da Física, Sociedade Brasileira de Física, 2005.

BONSIEPE, G. Do material ao digital. São Paulo: Blucher, 2015.

HUNTER F; BIVER, S; FUQUA, P. Luz - ciência e magia: guia de iluminação fotográfica. Tradução de $\mathrm{P}$. Z. Mello e R. Bonelli. 3. ed. Balneário Camburiú, SC: Photos, 2014.

KOLKO, J. Thoughts on Interaction Design: a collection of reflectios/written and compiled by Jon Kolko. 2. ed. Burlington: Morgan Kaufman, 2011.

LICHT, M. C; GONCALVES, B. S; PEREIRA, A. T. C; VIEIRA, M. L. H. O livro digital interativo como recurso educacional. In: IV Simpósio Internacional de Inovação em Mídias Interativas, 2016, Goiânia. Anais eletrônnicos... Goiânia: Media Lab - UFG, 2016. Disponível em: <https://siimi.medialab.ufg.br/p/16333anais-2016>. Acesso em:18 mar. 2017.

MEURER, H.; SZABLUK, D. Projeto E: aspectos metodológicos para o desenvolvimento de projetos dígito-virtuais. Ação Ergonômica - Ergodesign II. V.5, N. 2, 2010.

PORTUGAL, C. Questões complexas do design da informação e de interação. Info Design: revista brasileira de design da informação, S. L., v. 7, n. 2, p. 16, nov. 2010. Disponível em:

<http://www.infodesign.org.br/infodesign/article/view/8 9>. Acesso em: 21 ago. 2016.

PRÄKEL, D. Iluminação. Tradução de R. Pajuaba. Porto Alegre: Bookman, 2010.

PRODANOV, C. C; FREITAS, E. C. Metodologia do trabalho científico: métodos e técnicas da pesquisa e do trabalho acadêmico. 2. ed. Novo Hamburgo: Feevale, 2013.

PREECE, J; SHARP, H; ROGERS, Y. Design de interação: além da interação homem-computador. Porto Alegre: Bookman, 2005.

ROYO , J. Fundamentos do design: design digital. São Paulo: Rosari, 2008.

SAFFER, D. Designing for Interaction: Creating Innovative Applications and Devices. Berkeley: New Riders, 2010. 